\title{
MORFOLOGIA DE FRUTO, SEMENTE E PLÂNTULA DE Sebastiania commersoniana, EUPHORBIACEAE
}

\author{
Nelson Luiz Cosmo ${ }^{1}$, Antônio Carlos Nogueira ${ }^{2}$, Jeniane Gonçalves de Lima ${ }^{3}$, \\ Yoshiko Saito Kuniyoshi ${ }^{4}$ \\ ${ }^{1}$ Eng. Florestal, M.Sc., Doutorando em Engenharia Florestal, UFPR, Curitiba, PR, Brasil - ncosmo@ gmail.com \\ ${ }^{2}$ Eng. Florestal, Dr., Depto. de Ciências Florestais, UFPR, Curitiba, PR, Brasil - nogueira@ufpr.br \\ ${ }^{3}$ Eng $^{\text {a }}$ Florestal, UFPR, Curitiba, PR, Brasil - enainej@ hotmail.com.br \\ ${ }^{4}$ Naturalista, Dr ${ }^{\mathrm{a}}$, Depto. de Ciências Florestais, UFPR, Curitiba, PR, Brasil - yoshiko@ufpr.br \\ Recebido para publicação: 17/03/2009 - Aceito para publicação: 01/08/2009
}

\begin{abstract}
Resumo
Neste estudo, realizou-se a descrição morfológica de fruto, semente e plântula de Sebastiania commersoniana (Baillon) L. B. Smith \& R. J. Downs (branquilho), espécie arbórea de ampla distribuição no sul do Brasil, especialmente nas planícies aluviais da Floresta Ombrófila Mista. Foram obtidos frutos de dez matrizes em Engenheiro Bley, distrito da Lapa-PR. Para a descrição e ilustração do fruto e da semente, 50 amostras aleatórias foram analisadas. As sementes foram colocadas em rolo de papel-toalha, e em substrato comercial, postas para germinar em germinador Biomatic, a $25^{\circ} \mathrm{C}$. A espécie tem fruto deiscente do tipo esquizocarpáceo tricoca. A semente é carunculada, com hilo, rafe e micrópila visíveis sob lupa, tegumento papiráceo e endosperma oleaginoso, tendo dispersão autocórica e zoocórica. O embrião é dominante, axial, espatulado, com cotilédones foliáceos, cordiformes e eixo hipocótilo-radicular cilíndrico. A germinação iniciou-se por volta do terceiro e quarto dias após a instalação do teste, sendo a plântula epígea, fanerocotiledonar. Decorreram cerca de dez dias até a abertura dos paracotilédones e 15 dias até o início do desenvolvimento do epicótilo. Diversas características aqui descritas explicam, em parte, a eficiente e expressiva distribuição da espécie em sua área de ocorrência natural.

Palavras-chave: Morfologia vegetal; germinação; floresta aluvial; floresta ciliar.
\end{abstract}

\begin{abstract}
Morphology of the fruit, seed and seedling of Sebastiania commersoniana, Euphorbiaceae. This work consists on a morphological description of the fruit, seed and seedling of Sebastiania commersoniana (Baillon) L. B. Smith \& R. J. Downs (branquilho), tree species with wide distribution in southern Brazil, especially in the floodplains of the Mixed Ombrophylous Forest. For this, they were obtained fruits of ten trees in the district of Engenheiro Bley, municipality of Lapa-PR. For description and illustration of the fruits and seeds, 50 random samples were used. For germination, seeds were placed on paper-towel and on commercial substrate, in Biomatic germinator, at $25^{\circ} \mathrm{C}$. S. commersoniana has a dehiscent schizocarpic fruit, with three fruitlets. The albuminous seed has a papyraceous seed coat with caruncle, hilum, raphe and micropyle visible under magnifying glass. The embryo is dominant, axial, espatulate, with cordate, foliaceous cotyledons and cylindrical axis. The germination started up around the third and fourth days after the test installation and the seedling is epigeal, phanerocotyledonous. The opening of the paracotyledons and the beginning of the epicotyl development occurred about 15 days after the test installation. Several characteristics described in this paper explains, in part, the efficient and expressive distribution of this species in its area of natural occurrence.
\end{abstract}

Keywords: Plant morphology; germination; alluvial forest; riparian forest.

\section{INTRODUÇÃO}

Sebastiania commersoniana (Baillon) L. B. Smith \& R. J. Downs pertence ao clado Eurosideas I, ordem Malpighiales, família Euphorbiaceae, sendo o gênero muito comum nas florestas brasileiras (SOUZA; LORENZI, 2005). Trata-se de uma árvore conhecida como branquilho, de médio porte, 
semidecídua a decídua, heliófila (REITZ; KLEIN, 1988), tendo distribuição desde o Rio de Janeiro e Minas Gerais até o Rio Grande do Sul (LORENZI, 1992).

Apesar de ocorrer em diversas unidades fitogeográficas (ISERNHAGEN, 2001), é na formação aluvial da Floresta Ombrófila Mista que a espécie alcança sua maior expressão em termos de frequência e dominância. Graças a sua grande plasticidade ecológica, S. commersoniana é capaz de se estabelecer e se desenvolver plenamente nos solos das planícies aluviais, em condições bastante diversas, especialmente quanto ao regime hídrico, conforme constatado por Curcio (2006) e Barddal (2006), na planície do rio Iguaçu.

As sementes e a germinação dessa espécie têm sido estudadas por alguns autores. Santos; Aguiar (2005) analisaram o efeito da temperatura sobre a germinação de sementes de diferentes colorações. A qualidade fisiológica das sementes foi avaliada por Santos; De Paula (2005), utilizando teste de condutividade elétrica. Medeiros; Zanon (1998), por sua vez, investigaram aspectos referentes à conservação das sementes de $S$. commersoniana.

Devido a sua capacidade de tolerar os efeitos restritivos da saturação hídrica dos solos em que normalmente ocorre, alguns trabalhos têm enfocado também aspectos ecofisiológicos e morfoanatômicos de $S$. commersoniana, bem como suas respostas aos efeitos da anoxia e/ou hipoxia. De acordo com Kolb et al. (1998), ocorre uma série de alterações na estrutura anatômica de plantas jovens dessa espécie em resposta à saturação hídrica do solo, permitindo-lhe tolerar tanto as condições hipóxicas que se estabelecem após um alagamento, através de estruturas que possibilitam maior aeração das raízes, quanto as condições hiperóxidas no período de re-aeração. Barddal (2006), por sua vez, comprova a plasticidade de $S$. commersoniana em resposta às condições hídricas das planícies fluviais a partir do estudo da espécie em condições controladas, bem como da análise de sua distribuição em diversas unidades pedológicas.

Apesar da relevância desses trabalhos, pouco se conhece sobre os aspectos morfológicos dos frutos, das sementes e, especialmente, das plântulas de $S$. commersoniana. Segundo Oliveira; Pereira (1987), a interpretação de testes de germinação sob condições controladas de laboratório depende do conhecimento prévio da espécie, principalmente no que se refere às características morfológicas da semente e do desenvolvimento da plântula. Além disso, o conhecimento da morfologia de espécies nativas é de grande valia para o entendimento de sua autoecologia, bem como do seu comportamento e distribuição nos diferentes ecossistemas. Os dados obtidos nesse tipo de estudo têm, portanto, valor para a ecologia, a silvicultura e a conservação das espécies.

Visando preencher essa lacuna, no presente estudo teve-se como objetivo descrever a morfologia do fruto, da semente e da plântula de S. commersoniana, relacionando-a com aspectos ecológicos, considerando a expressiva ocorrência dessa espécie em formações florestais do sul do Brasil e a carência de estudos detalhados desses aspectos para essa espécie.

\section{MATERIAL E MÉTODOS}

Os frutos foram coletados em dezembro de 2004, de dez matrizes, dominantes e com bom estado fitossanitário, em um remanescente de Floresta Ombrófila Mista Aluvial, na localidade de Engenheiro Bley, no município da Lapa-PR, caracterizado, segundo Maack (1968), por clima subtropical úmido mesotérmico (Cfb), em $909 \mathrm{~m}$ de altitude, latitude $26^{\circ} 18^{\prime} \mathrm{S}$ e longitude $50^{\circ} 16^{\prime} \mathrm{W}$. A coleta foi realizada após a observação do ponto de maturação dos frutos, quando o pericarpo passa de verde a marrom, tornando-se seco. Os frutos foram levados para o Laboratório de Sementes Florestais da Universidade Federal do Paraná e colocados ao sol, sob peneira, para a liberação das sementes.

Foram utilizadas 50 amostras aleatoriamente para a descrição morfológica e ilustração dos frutos e sementes, realizando-se cortes transversais e longitudinais do material com lâmina de bisturi. Para as observações, foi utilizado microscópio estereoscópico. As medidas de comprimento, largura e espessura foram obtidas com auxílio de um paquímetro. Foi considerado para o comprimento, tanto dos frutos quanto das sementes, a distância entre o ápice e a base; para a largura, o lado mais largo; e para a espessura, o lado mais estreito.

Para caracterização do fruto, foram considerados detalhes externos e internos do pericarpo, referentes à textura, consistência, pilosidade, brilho, forma, número de sementes por fruto e deiscência. Das sementes, foram analisadas características externas (dimensões, cor, textura, consistência, forma, 
posição do hilo e da micrópila) e internas (presença ou ausência de endosperma, forma, cor, posição dos cotilédones, eixo hipocótilo-radicular e plúmula). Como referências para a descrição, foram consultados os trabalhos de Barroso et al. (1999) e Spjut (1994).

A fim de acompanhar o desenvolvimento da plântula, sementes foram colocadas em rolo de papel-toalha umedecido, em germinador do tipo Biomatic, a $25{ }^{\circ} \mathrm{C}$ (luz constante), e também em vasos plásticos com substrato comercial, mantidos em laboratório, em condições adequadas de luminosidade e ventilação. A descrição da plântula foi realizada conforme a nomenclatura proposta por Vogel (1980), e os aspectos morfológicos de paracotilédones e eofilos descritos de acordo com Hickey (1979).

\section{RESULTADOS E DISCUSSÃO}

\section{Fruto}

Considerando a classificação proposta por Barroso et al. (1999), S. commersoniana tem fruto subgloboso do tipo esquizocarpáceo tricoco, com deiscência marginal, quando maduro, nos cocos unisseminados, cada um dos cocos compostos por duas valvas (bivalvados). A superfície do fruto é glabra, lisa e brilhante, de coloração verde-clara enquanto imaturo, tornando-se castanho e fosco durante a maturação. As cocas têm o pericarpo dividido em duas zonas distintas: o exocarpo, de cor castanhoescura, e o endocarpo, de coloração castanho-clara no fruto maduro (Figura 1).

Esse tipo de fruto enquadra-se na categoria coccarium, de Spjut (1994), que revisou e reuniu inúmeras classificações de frutos, sendo definido pelo autor como "fruto derivado de um gineceu esquizocárpico, caracterizado por frutíolos que se abrem ao longo de suas suturas ventrais e, às vezes, das dorsais, como resultado da separação umas das outras ou de um eixo central".

A deiscência em $S$. commersoniana se dá de forma explosiva (balistocoria), num mecanismo que, segundo Berg (1975), citado por Barroso (1984), se originou apenas uma vez durante a história da evolução das angiospermas, de forma que todas as Euphorbiaceae com esse tipo de mecanismo de difusão das sementes estão relacionadas entre si e devem ter sido originadas de um ancestral comum. Para esse autor, essa é uma característica primitiva da família, desenvolvida em um clima com períodos distintos de seca, coincidentes com a época de maturação dos frutos.

$\mathrm{O}$ fruto maduro sofre, com a perda de turgor, um encurtamento não acompanhado pela coluna mediana rígida. Devido a isso, parte-se levemente na base, separando-se de seu cálice e entre os septos, junto à coluna, abaixo das placentas. As cocas ficam inteiras e no seu orifício ventral a saliência placentar se distende. Na sequência, cada coca fende-se do ápice para a base ao longo da sutura ventral e sobre a nervura média, na porção apical. Um movimento violento de tensão oposta libera a semente e separa parcialmente a coca em duas porções (valvas), ligadas pela base (BARROSO, 1984).

$\mathrm{Na}$ espécie estudada, durante a deiscência, as valvas normalmente permanecem ligadas na porção basal (Figura 1F), podendo, porém, eventualmente, se separar por completo (Figura 1G). Próximo às árvores matrizes, no momento da dispersão das sementes, é possível ouvir pequenos estalos resultantes da tensão que separa as cocas.

Segundo Barroso et al. (1999), nos frutos esquizocarpáceos das Euphorbiaceae, a formação das cocas está relacionada com a placentação axial atípica e a presença de carpóforo (coluna central), que permanece na planta após a deiscência. De acordo com os autores, a forma do carpóforo é uma característica que poderá ser explorada na sistemática das Euphorbiaceae, desde que analisada convenientemente, em um grande número de exemplos.

No caso de $S$. commersoniana, a coluna central permanece ligada ao pedúnculo e íntegra após a separação dos carpelos, sendo composta de um eixo central que se projeta em três alas finas e estreitas. No ápice do carpóforo permanece a saliência placentar, de forma mais ou menos piramidal, com os ângulos alternados em relação às abas da coluna.

Além da balistocoria (autocoria), a espécie apresenta também hidrocoria e zoocoria, como mecanismos secundários de dispersão. No sul do Brasil, a dispersão ictiocórica dessa espécie é feita especialmente pelo lambari (Astyanax spp.) e ornitocórica, por Columbina minuta (rolinha) (CARVALHO, 2003). 


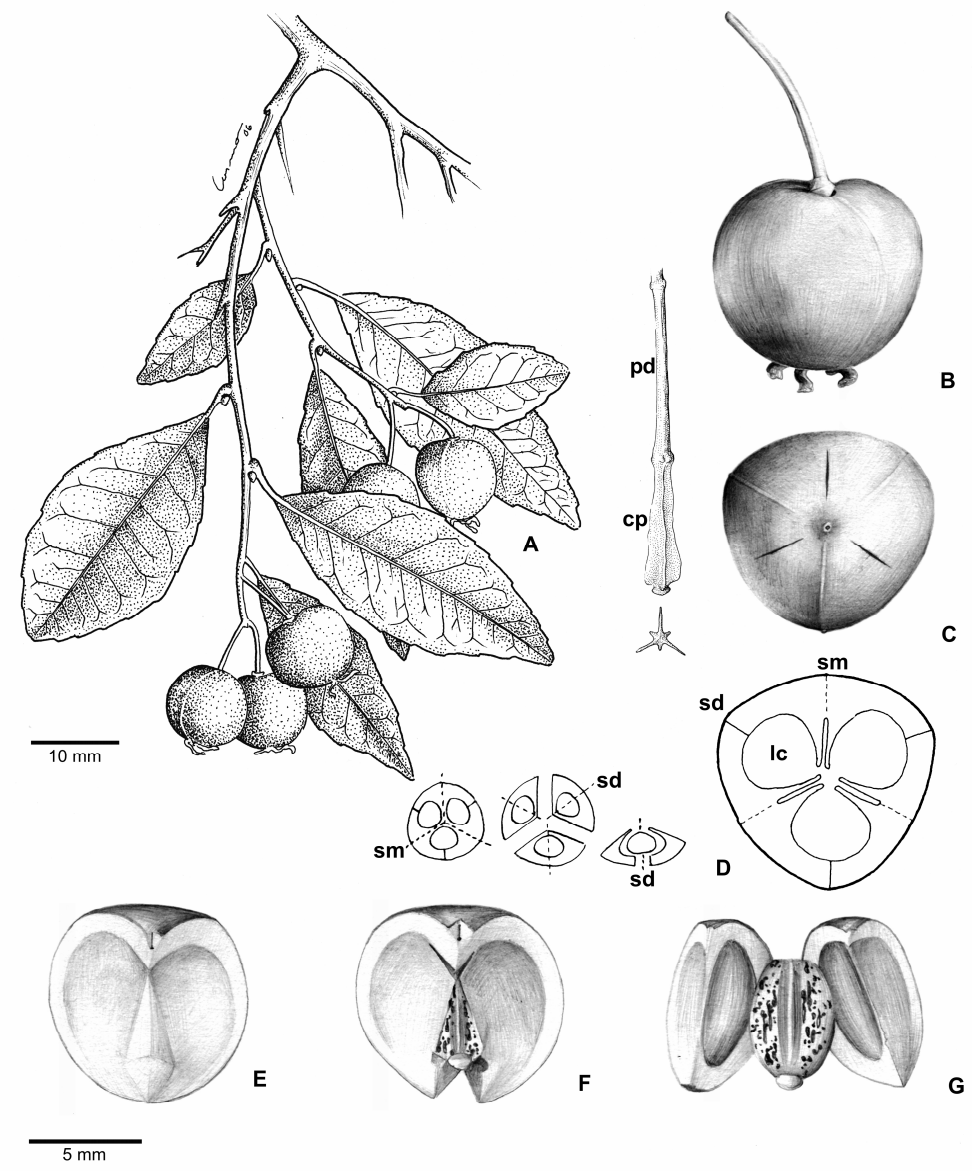

Figura 1. Fruto de Sebastiania commersoniana (Baillon) L. B. Smith \& R. J. Downs, Euphorbiaceae. A: ramo com frutos maduros; B: aspecto externo do fruto em vista lateral; C: ápice; D: representação esquemática do fruto em corte transversal e sequência de abertura durante a deiscência; E: detalhe da coca; F: abertura da coca a partir do ápice; G: divisão da coca em duas valvas, liberando a semente. cp: carpóforo; lc: lóculo; pd: pedúnculo; sd: sutura dorsal; sm: sutura marginal.

Figure 1. Fruit of Sebastiania commersoniana (Baillon) L. B. Smith \& R. J. Downs, Euphorbiaceae. A: shoot with ripe fruits; B: external aspect of the fruit in lateral view; C: apex; D: schematic representation of the fruit in cross section and opening sequence of dehiscence; E: detail of fruitlet (coca); F: fruitlet opening from the apex; G: fruitlet division in two valves, releasing the seed. cp: carpophorus; lc: locule; pd: petiole; sd: dorsal suture; sm: marginal suture.

\section{Semente}

A semente madura tem forma ovoide, com dorso convexo e face ventral levemente plana. Possui tegumento fino, papiráceo, com testa glabra, lisa e brilhante, normalmente com superfície mesclada de cor marrom e bege-clara, formando manchas irregulares (Figura 2A). Ocorrem também sementes de coloração uniforme (marrons).

O hilo é localizado no terço superior da face ventral e a rafe, caracterizada por uma sutura longitudinal, parte do hilo em direção à base da semente. No ápice encontra-se a carúncula, de cor begeclara e forma tetraédrica, em cujo centro localiza-se a micrópila. Tanto hilo como micrópila são visíveis sob lupa. Internamente observa-se o tégumen de cor marrom, pouco mais clara que da testa. $\mathrm{O}$ endosperma é oleaginoso, de consistência firme e coloração branca a creme. 

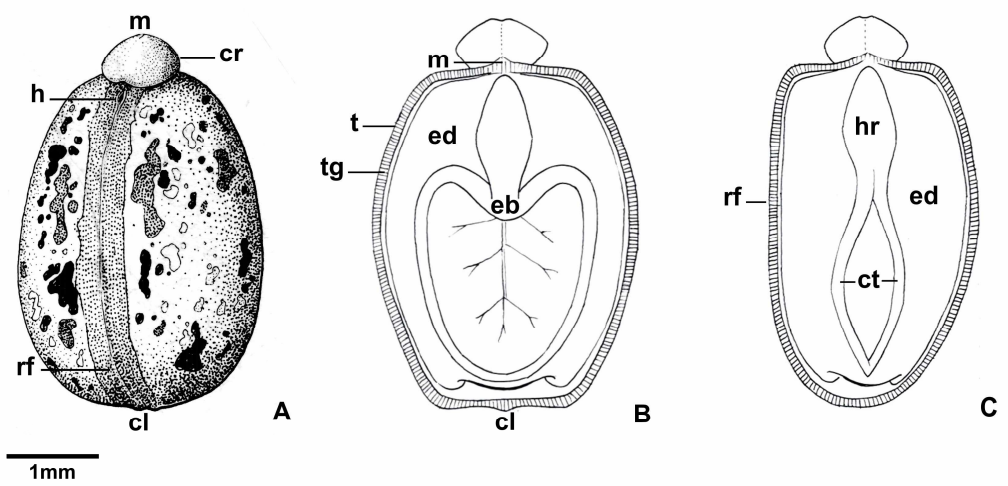

Figura 2. Morfologia da semente de Sebastiania commersoniana (Baillon) L. B. Smith \& R. J. Downs, Euphorbiaceae. A: aspecto externo em vista ventral; B: corte longitudinal paralelo à face ventral; $\mathrm{C}$ : corte longitudinal perpendicular à face ventral. cl: calaza; cr: carúncula; ct: cotilédones; eb: embrião; ed: endosperma; h: hilo; hr: eixo hipocótilo-radicular; m: micrópila; rf: rafe; t: testa; tg: tégumen.

Figure 2. Seed morphology of Sebastiania commersoniana (Baillon) L. B. Smith \& R. J. Downs, Euphorbiaceae. A: External aspect of seed in ventral view; B and C: longitudinal sections. cl: chalaza; cr: caruncle; ct: cotyledons; eb: embryo; ed: endosperm; h: hilum; hr: axis; m: micropyle; rf: raphe; t: testa; tg: tegmen.

A carúncula é um apêndice carnoso e cônico do tegumento, desenvolvido na extremidade da micrópila, tratando-se de uma característica típica de Euphorbiaceae (FERRI et al., 1969). De acordo com Mclean; Ivimey-Cook (1956), esse tipo de arilo atrai pássaros e, especialmente, formigas, que podem carregar sementes pequenas por distâncias consideráveis. Isso ocorre porque a carúncula contém reserva oleaginosa, constituindo um elaiossoma. Como exemplo, cita-se a semente de Ricinus communis (mamona), cuja carúncula, segundo Souza (2006), apresenta reserva oleaginosa nas células da epiderme e do parênquima.

A partir dessas informações, deve-se considerar a possibilidade de S. commersoniana apresentar dispersão por mirmecoria, além das diversas outras formas descritas anteriormente.

$\mathrm{Na}$ base da semente, internamente, nota-se a presença de uma estrutura circular, fina, de cor marrom, aderida à base do endosperma, provavelmente com origem na calaza.

Segundo Musil (1977), muitas espécies de Euphorbiaceae têm uma calaza proeminente, representada por uma área de coloração escura na extremidade oposta à cicatriz. Outro caráter distintivo das sementes dessa família é a presença de rafe, representada por uma linha escura, que se estende da micrópila até a área calazal, na extremidade oposta.

Observou-se que as sementes de $S$. commersoniana com coloração uniforme são, em geral, inviáveis. Esta pode ser uma característica importante a ser observada em estudos com outros lotes de sementes, para se verificar se esse fato ocorre com frequência na espécie. Santos; Aguiar (2005) observaram que a coloração do tegumento de sementes de $S$. commersoniana está associada à qualidade fisiológica delas, sendo as estriadas de melhor qualidade.

Tanto as sementes, como os frutos de $S$. commersoniana têm dimensões relativamente pequenas. Os valores de desvio padrão foram baixos, indicando a relativa homogeneidade da amostra obtida. As maiores variações foram encontradas para as características das sementes, dentre as quais a espessura teve a maior variação (Tabela 1).

\section{Embrião}

O embrião, que ocupa a maior parte da semente (dominante), é axial, invaginado, foliáceo e espatulado. Os cotilédones, de coloração pouco mais clara que a do endosperma, são foliáceos, planoconvexos, cordiformes e com ápice arredondado. $\mathrm{O}$ eixo hipocótilo-radicular tem forma cilíndrica, com ápice acuminado, consistência firme e cor creme (Figura 2B e C). 
Tabela 1. Dimensões (mm) de frutos e sementes de Sebastiania commersoniana (Baillon) L. B. Smith \& R. J. Downs, Euphorbiaceae.

Table 1. Fruits and seeds dimensions (mm) of Sebastiania commersoniana (Baillon) L. B. Smith \& R. J. Downs, Euphorbiaceae.

\begin{tabular}{lccccc}
\hline & $\begin{array}{c}\text { Valor } \\
\text { mínimo }\end{array}$ & Média & Valor máximo & Desvio padrão & $\begin{array}{c}\text { Coeficiente de } \\
\text { variação }\end{array}$ \\
\hline Frutos & & & & & \\
$\quad$ Comprimento & 6,98 & 7,73 & 8,36 & 0,25 & 3,23 \\
$\quad$ Largura & 8,14 & 8,91 & 9,72 & 0,31 & 3,36 \\
$\begin{array}{l}\text { Sementes } \\
\quad \text { Comprimento }\end{array}$ & 3,69 & 5,03 & 5,95 & & \\
$\quad$ Largura & 2,81 & 3,57 & 4,01 & 0,41 & 7,95 \\
$\quad$ Espessura & 2,11 & 2,95 & 3,41 & 0,23 & 6,44 \\
& & & & & \\
\hline
\end{tabular}

\section{Morfologia da plântula}

A germinação, evidenciada pela abertura da carúncula e protrusão da raiz primária (Figura 3A), ocorreu por volta do quarto dia após a instalação do teste nas sementes colocadas em papel-filtro, e após uma semana no substrato comercial. A descrição que segue e as ilustrações referem-se às plântulas que cresceram em substrato comercial. Quando comparadas a estas, as plântulas crescendo em papel-filtro desenvolveram maior quantidade de tricomas radiculares e um pequeno grau de estiolamento.

A plântula de S. commersoniana tem desenvolvimento epígeo, fanerocotiledonar. A partir do segundo dia após a emergência, é possível distinguir as partes do eixo: hipocótilo curvo, glabro, liso, de cor branca, raiz primária reta, branca, com tricomas pouco desenvolvidos e região da coifa acuminada. Delimitando hipocótilo e raiz, nota-se o colo, caracterizado por um sutil espessamento do eixo.

Quatro a cinco dias após a protrusão da raiz primária, com o aumento do volume do endosperma, ocorre a abertura longitudinal do tegumento (Figura 3B). Nesse estágio, o endosperma tem forma oval, cor branca e superfície lisa; os paracotilédones ainda não são visíveis.

Por volta do sétimo dia, os paracotilédones continuam ainda fechados e ocultos pelo endosperma (Figura 3C). Este, à medida que vai sendo consumido, adquire uma consistência gelatinosa, até que se tornem evidentes os paracotilédones. $\mathrm{O}$ hipocótilo torna-se gradativamente mais ereto e, aderidos aos paracotilédones, observam-se vestígios do endosperma, na forma de uma membrana translúcida (Figura 3D).

O paracotilédone tem forma obovada, com base aguda, ápice levemente truncado e margem inteira, e possui três nervuras principais saindo da base da lâmina (triplinérveo). Esta última característica, que ocorre em plântulas de muitos táxons (DUCKE, 1969; BURGER, 1972; VOGEL, 1980), foi também observada por Oliveira; Pereira (1987) e por Burger (1972) em diversas espécies de Euphorbiaceae, sugerindo que possa ser uma característica frequente também nessa família.

A partir da abertura dos paracotilédones, o epicótilo começa a se desenvolver e ocorre a emissão do primeiro eofilo, que é elíptico, com base aguda, ápice atenuado e margem serreada (Figura 3F). Notouse que, eventualmente, ocorre a emissão de um primeiro par oposto de eofilos. Essa tendência também foi observada em algumas espécies de Euphorbiaceae por Burger (1972), o que sugere que a disposição dos eofilos seja considerada com cuidado quando utilizada no reconhecimento de espécies ou em classificações morfo-funcionais de plântulas.

Tanto paracotilédones como eofilos são curto-peciolados, glabros, levemente discolores, com nervuras pouco evidentes. Na fase de tirodendro, que compreende o final do desenvolvimento do primeiro eofilo até a emissão dos primeiros nomofilos (SOUZA, 2003), os eofilos subsequentes apresentam características semelhantes ao primeiro, sendo apenas gradativamente maiores. Estes já são bastante semelhantes aos nomofilos de S. commersoniana, considerando-se a forma, cor e textura do limbo.

\section{Considerações ecológicas}

Os diversos mecanismos de dispersão das sementes de $S$. commersoniana, associados à alta porcentagem de germinação (SANTOS; AGUIAR, 2000; BARDDAL, 2006) e relativa resistência à desidratação (MEDEIROS; ZANON, 1998), provavelmente propiciam uma considerável distribuição espacial e temporal dos diásporos, diminuindo a competição intraespecífica e possibilitando maiores chances de estabelecimento das plântulas em condições favoráveis ao seu desenvolvimento. Destaca-se ainda que a espécie produz anualmente um elevado número de sementes viáveis, potencializando ainda mais tais vantagens. 


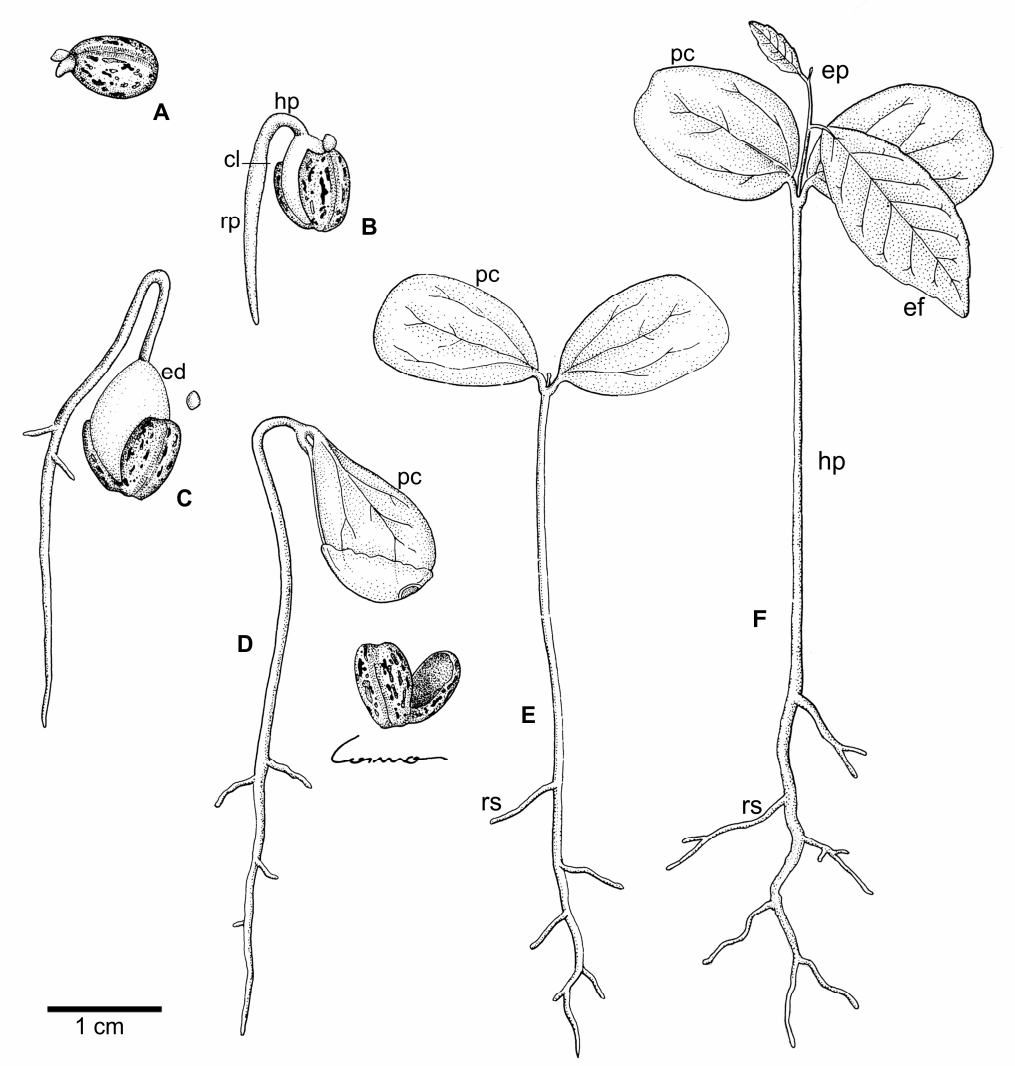

Figura 3. Morfologia da plântula de Sebastiania commersoniana (Baillon) L. B. Smith \& R. J. Downs, Euphorbiaceae. A: protrusão da raiz primária; B: abertura do tegumento quatro a cinco dias após a germinação; C: plântula com sete dias; D: plântula com dez dias; E: abertura dos paracotilédones; F: plântula com cerca de 20 dias. cl: região do colo; ed: endosperma; ef: eofilo; ep: epicótilo; hp: hipocótilo; pc: paracotilédone; rp: raiz primária; rs: raiz secundária.

Figure 3. Seedling morphology of Sebastiania commersoniana (Baillon) L. B. Smith \& R. J. Downs, Euphorbiaceae. A: primary root protrusion; B: opening of the seed coat four to five days after germination; C: seedling with seven days; D: seedling with ten days; E: opening of the paracotyledons; F: seedlings with about 20 days; cl: the collet region; ed: endosperm; ef: eophyll; ep: epicotyl; hp: hypocotyl; pc: paracotyledons; rp: primary root; rs: secondary root.

A plântula apresenta diversas características morfo-funcionais que são muito frequentes em espécies heliófilas, tais como o desenvolvimento epígeo, fanerocotiledonar, e a presença de paracotilédones (VOGEL, 1980; RESSEL, et al., 2004; WRIGHT et al., 2000; IBARRA-MANRÍQUEZ et al., 2001). Estes, enquanto envoltos pelo endosperma, têm a função de transferir as reservas alimentares para os outros órgãos da plântula (VOGEL, 1980). Uma vez expandidos e expostos, os paracotilédones assumem a função de fotossíntese e passam a sustentar o desenvolvimento dos eofilos.

Além disso, segundo Ibarra-Manríquez et al. (2001), a capacidade de dispersão das espécies com essas características, em geral, e nas pioneiras em particular, envolve geralmente uma associação entre vetores bióticos e abióticos, tal como ocorre em S. commersoniana, considerando seus diversos mecanismos de dispersão de sementes.

Tais fatores certamente propiciam um rápido estabelecimento e crescimento inicial da planta, tornando-a mais competitiva e menos vulnerável a fatores adversos, como o ataque de pragas e herbívoros, e às instabilidades físicas de determinados ambientes em que a espécie ocorre, como no caso dos solos de planície, sujeitos à inundação e deposição de sedimentos. 
Segundo Vogel (1980), a velocidade de crescimento das plântulas nos primeiros estágios de estabelecimento é principalmente determinada pelo conteúdo de reserva da semente e propriedades genéticas. O desenvolvimento posterior depende da reserva alimentar presente na plântula e/ou assimilados produzidos pelos paracotilédones e eofilos. Também têm considerável influência nesse processo os fatores externos, como a incidência de luz, por exemplo, especialmente em plântulas providas de paracotilédones.

Certamente, cada uma dessas características contribui para que a espécie se torne competitiva e, no conjunto, justificam, em parte, o grande destaque de $S$. commersoniana nos diversos ambientes em que ocorre. Destaca-se principalmente sua expressiva dominância como pioneira em determinadas situações em que poucas espécies são capazes de se desenvolver, como no caso dos solos mal drenados das planícies fluviais da Floresta Ombrófila Mista (CURCIO, 2006).

\section{CONCLUSÕES}

- Diversos caracteres morfológicas e funcionais dos frutos, sementes e plântulas de $S$. commersoniana descritos neste trabalho são relevantes para a taxonomia e silvicultura da espécie.

- O reconhecimento de tais atributos contribui também para o entendimento da sua autoecologia e dos fatores que podem ter influência no seu estabelecimento, desenvolvimento inicial e, por consequência, em sua distribuição geográfica.

\section{REFERÊNCIAS}

BARDDAL, M. L. A influência da saturação hídrica na distribuição de oito espécies arbóreas da Floresta Ombrófila Mista Aluvial do rio Iguaçu, Paraná, Brasil. 115 f. Tese (Doutorado em Engenharia Florestal) - Setor de Ciências Agrárias, Universidade Federal do Paraná, Curitiba, 2006.

BARROSO, G. M. Sistemática de angiospermas do Brasil. Viçosa: Universidade Federal de Viçosa, v. 2, 1984. $377 \mathrm{p}$.

BARROSO, G. M.; MORIM, M. P.; PEIXOTO, A. L.; ICHASO, C. L. F. Frutos e sementes: morfologia aplicada à sistemática de dicotiledôneas. Viçosa: Universidade Federal de Viçosa, 1999. 443 p.

BURGER, H. Z. N. Seedlings of some tropical trees and shrubs mainly of South East Asia. Wageningen, $1972.399 \mathrm{p}$.

CARVALHO, P. E. R. Espécies arbóreas brasileiras. Brasília: Embrapa Informação Tecnológica; Colombo: Embrapa Florestas, v. 1, 2003. 1039 p.

CURCIO, G. R. Relações entre Geologia, Geomorfologia, Pedologia e Fitossociologia nas planícies fluviais do rio Iguaçu, Paraná, Brasil. Tese (Doutorado em Engenharia Florestal) - Setor de Ciências Agrárias, Universidade Federal do Paraná, Curitiba, 2006.

DUCKE, J. A. On tropical tree seedlings: seeds, seedlings, systems and systematic. Annals of the Missouri Botanical Garden, St. Louis, v. 55, p. 125-61, 1969.

FERRI, M. G.; MENEZES, N. L.; SCANAVACA, W. R. M. Glossário de termos botânicos. São Paulo: Universidade Federal de São Paulo, 1969.

HICKEY, L. J. A revised classification of the architecture of dicotyledonous leaves. In: METCALFE, C. R.; CHALK, L. (eds.). Anatomy of the dicotyledons: systematic anatomy of leaf and stem, with a brief history of the subject. Oxford: Clarendon Press, 1979. v. 1. p. 25-39.

IBARRA-MANRÍQUEZ, G.; RAMOS, M. M.; OYAMA, K. Seedling functional types in a lowland rain forest in Mexico. American Journal of Botany, Columbus, v. 88, p. 1801-1812, 2001.

ISERNHAGEN, I. A fitossociologia florestal no Paraná e os programas de recuperação de áreas degradadas: uma avaliação. 219 f. Dissertação (Mestrado em Botânica) - Setor de Ciências Biológicas, Universidade Federal do Paraná, 2001. 
KOLB, R. M.; MEDRI, M. E.; BIANCHINI, E.; PIMENTA, J. A.; GILONI P. C.; CORREA, G. T. Anatomia ecológica de Sebastiania commersoniana (Baillon) Smith \& Downs (Euphorbiaceae) submetida ao alagamento. Revista Brasileira de Botânica, São Paulo, v. 21, n. 3, 1998.

LORENZI, H. Árvores brasileiras: manual de identificação e cultivo de plantas arbóreas nativas do Brasil. Nova Odessa: Plantarum, 1992.

MAACK, R. Geografia física do estado do Paraná. Curitiba: BADEP/UFPR/IBPT, 1968. 350 p.

MCLEAN, R. C.; IVIMEY-COOK, W. R. Textbook of theoretical botany. London, v. 2, p. 1481-1571, 1956.

MEDEIROS, A. C. de S.; ZANON, A. Conservação de sementes de branquilho (Sebastiania commersoniana (Baillon) L. B. Smith \& R. J. Down) e de pinheiro-bravo (Podocarpus lambertii KLOTZCH EX E NDL.), armazenadas em diferentes ambientes. Boletim de Pesquisa Florestal, Colombo, n. 36, p. 57-69, 1998.

MUSIL, A. Identificação de sementes de plantas cultivadas e silvestres. AGIPLAN, Brasília, 1977. 299 p.

OLIVEIRA, E. de C.; PEREIRA, T. S. Euphorbiaceae: morfologia da germinação de algumas espécies. Revista Brasileira de Sementes. Brasília, v. 9, n. 1, 1987.

REITZ, R.; KLEIN, R. M. Flora ilustrada catarinense: euforbiáceas. Itajaí: Herbário Barbosa Rodrigues, 1988.

RESSEL, K.; GUILHERME, F. A. G.; SCHIAVINI, I.; OLIVEIRA, P. E. Ecologia morfo-funcional de plântulas de espécies arbóreas da Estação Ecológica do Panga, Uberlândia, Minas Gerais. Revista Brasileira de Botânica, São Paulo, v. 27, n. 2, 2004.

SANTOS, S. R. G. dos; AGUIAR, I. B. de. Efeito da temperatura na germinação de sementes de Sebastiania commersoniana (Baillon) Smith \& Downs separadas pela coloração do tegumento. Scientia Forestalis, Piracicaba, n. 69, p. 77-83, 2005.

. Germinação de sementes de branquilho (Sebastiania commersoniana (Baill.) Smith \& Downs) em função do substrato e do regime de temperatura. Revista Brasileira de Sementes, Campinas, v. 22, n. 1, p. 120-126, 2000.

SANTOS, S. R. G. dos; DE PAULA, R. C. Teste de condutividade elétrica para avaliação da qualidade fisiológica de sementes de Sebastiania commersoniana (Bail.) Smith \& Downs, Euphorbiaceae. Revista Brasileira de Sementes, Campinas, v. 27, n. 2, p. 136-145, 2005.

SOUZA, L. A. de. Anatomia do fruto e da semente. Ponta Grossa: Universidade Estadual de Ponta Grossa, 2006. 200 p.

Morfologia e anatomia vegetal: célula, tecidos, órgãos e plântula. Ponta Grossa: Universidade Estadual de Ponta Grossa, 2003. 259 p.

SOUZA, V. C.; LORENZI, H. Botânica sistemática: guia ilustrado para identificação das famílias das angiospermas da flora brasileira, baseado em APGII. Nova Odessa: Instituto Plantarum, 2005. 640 p.

SPJUT, W. R. A systematic treatment of fruit types. New York: The New York Botanical Garden, 1994. $180 \mathrm{p}$.

VOGEL, E. F. Seedlings of dicotyledons: structure, development, types: descriptions of 150 woody Malesian taxa. Wageningen: Centre for Publishing and Documentation, 1980.

WRIGHT, I. J.; CLIFFORD, H. T.; KIDSON, R.; REED, M. L.; RICE, B. L.; WESTOBY, M. A survey of seed and seedling characters in 1744 Australian dicotyledon species: cross-species trait correlations and correlated trait-shifts within evolutionary lineages. Biological Journal of the Linnean Society of London, London, n. 69, p. 521-547, 2000. 
